\title{
THE OCCURRENCE AND FUNCTION OF OIDIA IN THE HYMENOMYCETES ${ }^{1}$
}

\section{Harold J. Brodie}

IN THE latter half of the eighteenth century the early mycologists, influenced by their knowledge of higher plants, searched for sexual organs in the fungi analogous to those with which they were familiar among the phanerogams. Micheli (1729) had declared that the cystidia in the hymenium of a mushroom are apetalous flowers. Bulliard (1791) believed the cystidia to be male organs and described the manner in which their seminal fluid poured out over the basidia to fertilize the basidiospores.

It has long been known that the mycelium of many fungi breaks up into short segments generally called oidia. Such commonly occurring structures as oidia did not pass unnoticed in the search for sexual organs and the questions of the significance and probable function of oidia engaged the attention of a number of workers. Tulasne (1851) discovered in the lichens and in many of the Ascomycetes structures in which were borne small spores usually incapable of germination. These spores he called spermatia and he considered that they are male cells. Later he discovered similar structures in the Tremellales and concluded that the pycniospores of the Uredinales are also true male cells (Tulasne, 1859).

Hofmeister (1852) showed that in ferns the sex organs are developed not on the spore-bearing generation but on the prothallium which is independent of the sporophyte. This discovery provided mycologists with a new clue and they began to search for sexual organs in the higher fungi not on the pileus but on the vegetative mycelium.

Karsten (1860) described finding on the mycelium of Psalliota campestris reniform "female" cells which were fertilized by "male" elements. At the same time Oersted (1865) thought he saw female cells fertilized by ordinary hyphae.

The suggestion that the commonly occurring oidia might be male cells was made again by Rees (1875), who germinated basidiospores of Coprinus stercorarius $^{2}$ and observed that, on the young mycelia, there were developed short branches bearing small cells which became detached from the parent filament. These cells failed to germinate and Rees believed that they must be spermatia. Seeing large vesicular cells on the same mycelium, he thought he had also found the female organs.

Van Tieghem (1875a. b) reported similar spermatia and female organs in Coprinus ephemeroides and $C$.

1 Received for publication February 14, 1935.

Papers from the Department of Botany and the Herbarium of the University of Michigan, No. 526.

2 Both Rees and Van Tieghem used the name Coprinus stercorarius to apply to an oidium-producing fungus. Brefeld believed that these workers probably had reference to $C$. lagopus. The true $C$. stercorarius does not produce oidia and is homothallic. radiatus. He believed that the spermatia became attached to and emptied their contents into the vesicular female cells. The female cells, after being fertilized, gave rise to branched hyphae which developed into the fruit body. The observations of contemporary workers, such as Eidam (1875) and Kirchner (1875), seemed to support the report of Van Tieghem.

However, Van Tieghem (1876) was obliged to change his views. He sowed the spermatia of Coprinus plicatilis in a drop of nutrient medium and saw the small cells germinate, producing branched mycelia. Because the small cells germinated, he declared that they do not serve as spermatia but reproduce the fungus in an asexual manner, in this respect being comparable with conidia. The fact that the oidia did sometimes fuse with large vesicular cells was of no special significance, Van Tieghem decided, since the oidia could fuse equally well with any cell of the mycelium. He concluded that the supposed sexual organs in the Basidiomycetes are in reality merely vegetative structures.

Cornu (1875) succeeded in germinating the socalled spermatia of certain of the Ascomycetes and he, like Van Tieghem, considered that the spermatia serve only for vegetative reproduction and are comparable with conidia.

This idea was championed by Brefeld (1877, 1889), who discredited theories of sexuality in the Basidiomycetes and who saw no difference between the origin of basidiospores and that of conidia. His attention was much attracted by oidia and he demonstrated their manner of occurrence in more than thirty species of the Hymenomycetes. ${ }^{3}$ He announced (1877) that although he had made numerous attempts to do so, he had been unable to germinate the oidia of Coprinus lagopus, and from this he concluded that oidia are vestigial structures which no longer possess the power of germinating and which, therefore, cannot be regarded as functional spermatia.

Richard Falck (1902), a student of Brefeld, demonstrated that oidia are to be found on the mycelium of species of Mucor, Dacryomyces, Ascobolus, Coprinus, Collybia and Hypholoma. Like Brefeld, Falck concluded that the oidia of most of the coprophilous species of the Basidiomycetes have lost the ability to germinate.

The discovery of Schmitz (1880) of paired nuclei in the mycelium and urediniospores of Coleosporium campanulae was the begininng of a long series of cytological investigations which threw light upon the question of sexuality in the Basidiomycetes. Through the researches of Rosen, Dangeard, Sappin-Trouffy, Maire, and others there evolved a new theory of

\footnotetext{
:For a list of these species, see Brodie, H. J. (1931).
}

[The Jourxal for April (23: 235-308) was issued June 15, 1936.]

american Jocrial of Botany, Vol. 23, No. 5, Max, 1936 
sexuality which was announced by Bensaude (1918) and independently by Kniep (1917).

By cytological and experimental investigations, Bensaude showed that Coprinus lagopus ${ }^{4}$ is heterothallic. She obtained two cultures, each of which was derived from a single basidiospore. These mycelia remained for eight months in the primary or haploid condition-i.e., they produced no clamp-connections, had but a single nucleus in each cell, and produced no fruit bodies whatever. However, when the two mycelia were allowed to fuse, there was developed a secondary or dicaryon mycelium ${ }^{5}$ which bore clampconnections. Bensaude showed that the paired nuclei of the dicaryophyte divide conjugately and that each division of the conjugate pair or dicaryon is associated with the formation of a clamp-connection. The two nuclei which fuse in the basidium are the descendants of a single pair of nuclei belonging to compatible strains.

Bensaude also studied the structure and development of the oidia of Coprinus lagopus. In certain culture tubes she saw some of the oidia germinate and produce short germ tubes which exhibited the ability to fuse with any of the cells of the parent mycelium. She had also noticed that when she planted two mycelia of opposite strain, $A$ and $B$, near one another on nutrient agar, occasionally one of the mycelia became binucleate before it had come into contact with the other one. She explained this occurrence by supposing that the oidia from one mycelium, $B$, floated across the gap between $A$ and $B$ in the surface film of water covering the agar. When the germ tubes of the oidia from mycelium $B$ fused with mycelium $A$, the latter was converted into dicaryon mycelium.

As a result of her investigations, Bensaude declared that the oidia of Coprinus lagopus may be the means whereby the monocaryon mycelium is transformed into dicaryon mycelium.

Since 1918 much attention has been given to the study of sexuality in the Hymenomycetes. It is not the writer's intention to review in this paper all the recent literature dealing with this very complex sub-

4 Bensaude referred to this fungus as $C$. fimetarius, which has been shown to be identical with the $C$. lagopus of Brefeld, Buller and others. For a discussion of this matter, see Buller's Researches on Fungi (1931).

5 Throughout this paper the terms monocaryon mycelium and dicaryon mycelium will be employed instead of the older terms haploid and diploid. One may also refer conveniently to a monocaryophyte and a dicaryophyte. It would appear desirable to indicate a distinction between a thallus provided with true diploid nuclei (such as is found in the higher plants and animals) and one provided with dicarya. We do not as yet know whether or not the influence exercised by the two nuclei of a dicaryon upon the cell which contains them is the same as that of a single diploid nucleus.

In adopting this terminology the writer is following the suggestion given by Professor Bessey in his recently published Textbook of Mycology (1935).

To be entirely consistent, one ought not then to refer to diploidization. The writer prefers, however, not to suggest a substitute for this most convenient term. ject. However, the researches referred to below will suffice to show how the more recent developments in experimental work concerning sexuality in the higher fungi are connected with the problem of the function of the oidia.

Vandendries (1923) published an account of the sexual behavior of the heterothallic agarics Collybia velutipes, Hypholoma fasciculare, and Panaeolus campanulatus and showed that oidia are produced on the monocaryon mycelium of each of these species. Some oidia of $P$. campanulatus were isolated from a mycelium called Thallus 17 , a strain which could be recognized by certain specific cultural characters. When the oidia taken from this mycelium were sown on fresh culture medium, a mycelium was obtained which bore the characters of the parent. From this and other experiments, Vandendries concluded: "L'oidie, élément haploïde, peut jouer un rôle de multiplication purement végétative et propager un thalle primaire gardant les proprietées de son ascendant: elle peut aussi fertiliser un thalle haploide de sexe contraire, et présente alors tous les attributs d'un gaméte."

Craigie (1927) discovered that the pycniospores of the Uredinales are functional. He found that the pycniospores are effective diploidizing agents after transference by hand or by insects from a $(+)$ mycelium to a (-) mycelium, or vice versa.

Professor A. H. R. Buller suggested to the writer that the oidia of the Hymenomycetes, like the pycniospores of the Uredinales, after transference from a mycelium of one strain to a mycelium of compatible strain might germinate, and the germ tubes or mycelia which developed from the oidia might bring about the diploidization of the mycelium to which they had been transferred. This suggestion was verified by the writer using the well known agaric Coprinus lagopus (Brodie, 1931).

Later, Dowding (1931) found that in one of the Ascomycetes, Ascobolus stercorarius, the oidia function in a way similar to those of the Hymenomycetes.

An interesting extension of this idea is the research of Drayton (1932) on Sclerotinia Gladioli Massey. It was shown that when this fungus is isolated from Gladiolus and other cormous and bulbous plants, mycelium is obtained which bears no apothecia but which produces a stromatic layer and from the latter there develop columnar receptive bodies. Microconidia are also produced by the fungus from small club-shaped conidiophores. When the microconidia are transferred to the receptive bodies, the latter develop into apothecia which are typical of those found in Sclerotinia, which fact has led to the placing of the fungus in that genus. The receptive bodies of one mycelium do not react with their own microconidia but only with microconidia taken from a mycelium of reactive potentiality opposite to the first. It thus appears that in Sclerotinia Gladioli the microconidia of one mycelium are capable of spermatizing the receptive bodies of another, and that the sexual mechanism resembles what Craigie (1927) and Andrus (1931) have found in the Rust Fungi. 
In the Ascomycetes some difficulty is encountered in interpreting the function of the various types of secondary spores - macroconidia and microconidia. Working with Pleurage anserina, Ames (1932) found that although the mycelia produced by the normal binucleate ascospores give rise to mycelia which produce perithecia, the dwarf uninucleate spore develops into a mycelium which fails to produce perithecia but which produces microspores and large ascogonia with trichogynes. The microspores borne on one mycelium do not fertilize the ascogonia borne on the same mycelium, but cross fertilization can take place if spermatia (microspores) from one culture are transferred to another of compatible strain. From the ascogonia which have been fertilized in this manner, mature perithecia develop. The spermatia do not germinate on nutrient substrata, but, when placed on compatible ascogonia, cause the development of these into perithecia. Ames claims that the nuclei of the spermatia enter the trichogyne very soon after the spermatia come into contact with it, and he concludes that they function as true spermatia and not as conidia.

A different situation is found in Neurospora sitophila, now so well known through the work of Dodge (1932). Microconidia are also produced by this ascomycete, but they germinate and give rise to mycelia which are like mycelia derived from ascospores or from macroconidia. In addition, the microconidia from one mycelium are capable of acting as diploidizing agents when transferred to a mycelium of a different but compatible strain. The microconiclia have therefore both a sexual and an asexual function. The bearing of the results of Drayton, Ames, and Dodge upon the interpretation of sexual phenomena and upon attendant nomenclatural difficulties will be discussed in the concluding section of this paper.

It will be shown later (p. 324) that about twenty species of heterothallic Hymenomycetes are known to produce oidia. The fact that these spores occur so commonly makes the question of their function an important one. The investigations recorded in this paper were undertaken with a view to ascertaining: (1) whether or not the dictum of Brefeld that the oidia of the Hymenomycetes are to be regarded as vestigial structures which have lost the power of germinating is true or false; (2) whether or not the production of oidia is dependent upon the environmental conditions surrounding the mycelium on which the oidia are developed; (3) whether or not oidia occur on hoth monocaryon and dicaryon mycelia and in both homothallic and heterothallic species: (4) whether or not the oidia play a definite rôle in the life history and diploidization process in the Hymenomycetes in general as has been suggested by earlier workers and by the author's own work on Coprinus lagopus.

Since the word oidium has been applied rather loosely to a variety of spore forms in fungi, it may be well to state that oidia, as this term is understood by the writer and used in this communication, are short, hyaline, rod-shaped cells with thin walls and dense protoplasmic contents. Oidia are not to be thought of as resting spores although they may be capable of retaining their vitality for a considerable length of time. Thus Falek (1902) found that the oidia of Lenzites sepiaria, preserved for a year in an atmosphere dried with calcium chloride, germinated at once when placed in favorable environment. The writer believes that, in general, oidia retain their vitality for only a short time, possibly a few days.

Oidia are formed by the breaking up of mycelium into segments. In the formation of typical oidia, a hypha which is destined to segment ceases to elongate. Beginning at the apex, a process of segmentation sets in by which the hypha becomes converted into a chain of short cells. Commonly, no transverse walls are laid down in the oidial hypha; the short segments of protoplasm, isolated from one another by the formation of gaps or vacuoles, become oidia. Occasionally from one to three true transverse septa are formed in the oidial hypha before the segmentation of protoplasm begins. Whereas the formation of conidia is typically exogenous, the formation of oidia is endogenous.

From what has preceded, it should be clear what the writer has in mind when using the word oidium. A search through the literature reveals the fact that the words oidium, conidium, chlamydospore, and gemma have been used loosely and interchangeably. Oidia seems to be the most suitable term to apply to the secondary spores described in this paper.

It should be noted that under certain circumstances the formation of oidia occurs on mycelia which do not ordinarily produce them. Brefeld (1877) has shown that many kinds of mycelia break up into chains of oidia when the food supply of the medium on which the mycelia have been growing has been exhausted-i.e., in stale cultures. In the agarics Coprinus lagopus, Collybia velutipes, Lenzites betulina, and others studied by the writer, the production of oidia is a specific function of the actively growing mycelium; oidia are produced as abundantly when the mycelia are transferred to fresh medium as when they have been growing for a long time upon it. The continued and undiminished formation of oidia exhibited by these species when grown in culture is not to be confused with the occasional formation of oidia by certain fungi under unfavorable and highly artificial conditions of growth. It is the former type of oidia production with which the writer has concerned himself; all the species of fungi hereinunder recorded as producing oidia do so under the optimum conditions of growth

Studifs of Collybia velutipfs (Curt.) Fr., with SPECIAL REFERENCE TO THE FUNCTION, DEVELOPMENT, AND SEXUALITY OF THF OIDIA. This fungus, which is frequently collected and readily grown in culture, has been the subject for considerable study. The literature dealing with the biology of $C$. velutipes is much too voluminous to be reviewed in detail here, and mention will be made of only a few of the most im- 


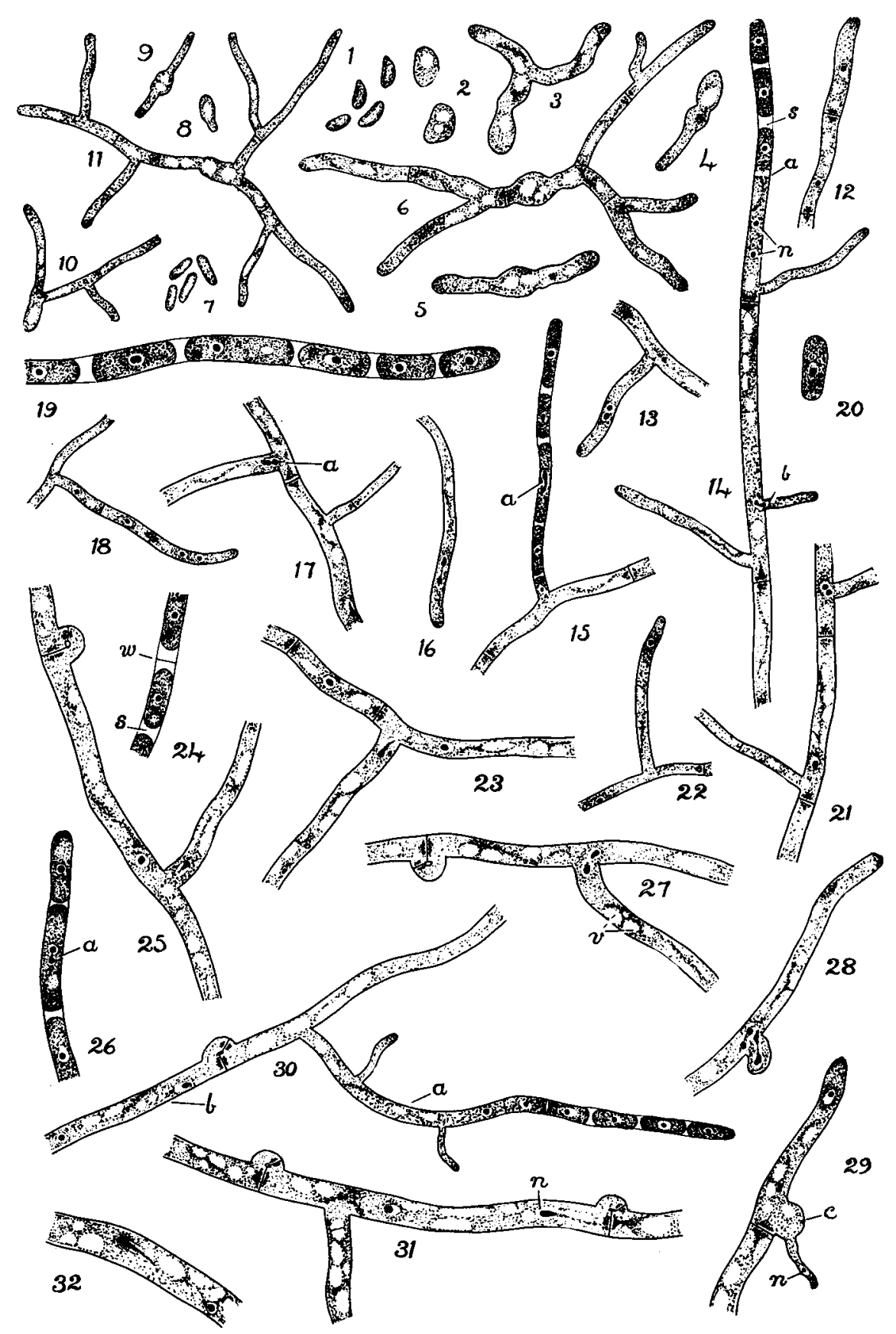

Fig. 1-32. Collybia velutipes.-Fig. 1-6. Stages in germination of basidiospores.-Fig. 7-11. Stages in germination of oidia taken from a monocaryon mycelium.-Fig. 12. Tip of young hypha of monocaryon mycelium showing one nucleus in each of the two cells.-Fig. 13. Short hyphal branch on a monocaryon mycelium showing a pair of nuclei probably produced by a recent division.-Fig. 14. Uninucleate hypha beginning to break up into oidia at its apex: $s$, clear area between two recently formed oidia; $a$, fine line indicating break in protoplasm during oidia formation; $n$, pair of sister nuclei, the distal one of which may become isolated in the next formed oidium and the proximal one of which may divide again; $b$, nucleus undergoing division.-Fig. 15. Chain of oidia containing a long segment in which nucleus $a$ is dividing prior to division of segment into two or more oidia. - Fig. 16. Young hypha of a monocaryon mycelium showing dividing nucleus at its apex.-Fig. 17. Portion of a uninucleate hypha showing nucleus a undergoing division.-Fig. 18. Uninucleate hypha with three cells; nucleus of apical cell has divided giving two sister nuclei; hypha probably about to break up into oidia. - Fig. 19. Chain of oidia illustrating dense protoplasmic contents of oidia, presence of a single nucleus in each oidium, and indistinctness of wall of oidial hypha between oidia.-Fig. 20. Single oidium freed from the hypha in which it was formed.-Fig. 21. Portion of uninu- 
portant papers, particularly those which deal with the fungus in pure culture.

The fact that the mycelium of $C$. velutipes breaks up into chains of oidia was first recorded by Van Tieghem (1875a). Although he had previously concluded that the oidia of this fungus may be regarded as "male" cells, in 1876 he declared that their function is purely that of vegetative reproduction. The presence of oidia was also noticed by Constantin and Matruchot (1894), who gave an account of the fungus and described a method for obtaining fruit bodies in artificial culture. Brefeld (1889) described the structure of the mature carpophore and illustrated the oidia produced on the vegetative mycelium. Stewart (1918) gave a general account of the biology of the Collybia as it occurs in New York State. He described and illustrated some curious malformed fruit bodies. Teratological forms of fruit bodies have also been discussed by Buller (1924).

The sexual condition in $C$. velutipes was first investigated by Kniep (1920), who listed it with twenty other species of the Hymenomycetes which he had shown to be heterothallic. Vandendries (1923) confirmed Kniep's report, and, by obtaining single spore mycelia and pairing them with one another, was able to show that the fungus belongs to the tetrapolar type. A few of the mycelia grown from single spores exhibited very irregular behavior in their pairing reactions and were considered by him as mutations similar to those which had been described by Kniep for Schizophyllum commune (1920). ${ }^{6}$

Funke (1924) isolated the four spores from individual basidia of $C$. velutipes and demonstrated that the segregation of sex factors in this fungus takes place in the second division of the fusion nucleus.

Zattler (1924) published an account of his extensive genetical studies of $C$. velutipes. He demonstrated that the inheritance of the brown color of the mycelium is determined by two pairs of factors $(R, r$, $V$ and $v$ ) which are quite independent of the two pairs of sex factors. The presence of either of the two dominant factors $R$ and $V$ causes a mycelium

\footnotetext{
6 Recent research has shown that many such irregularities signify but a transient instability and may not be true mutations. For a detailed discussion of this subject, see Vandendries and Brodie (1933).
}

to possess a brown coloration, but $R$ gives a more intense color than $V ; R V$ haplophytes are intense brown, $R v$ and $r V$ haplophytes are light brown of different intensities, while $r v$ haplophytes are pure white.

Collybia velutipes resembles Coprinus lagopus, previously studied by the writer (Brodie, 1931), in being heterothallic and in developing oidia on its mycelium, and for these reasons it was selected for further study. The present paper is concerned with the question of development, structure and function of the oidia produced by Collybia velutipes. The fact that in this fungus oidia are developed on the dicaryon mycelium as well as on the monocaryon mycelium has lent additional interest to this study.

The problem of the function of the oidia in the Hymenomycetes was first suggested to the writer in 1930 by Professor A. H. R. Buller, of the University of Manitoba. Its solution has been made possible through the writer's appointment to the Newcombe Fellowship in Plant Physiology at the University of Michigan. Professor E. B. Mains, of the Department of Botany of that university, has kindly given assistance in many ways throughout the course of the work. Through the kindness and hospitality of Dr. René Vandendries, of Belgium, part of the work was done in collaboration with him. It is a pleasure to acknowledge the aid given by the persons mentioned and the support and sponsorship of the University of Michigan.

The publication of this work has been made possible through financial aid generously given by $\mathrm{Mr}$. Thomas Brodie, of Winnipeg, Canada, and Dr. Howard A. Kelly, of Baltimore, Maryland. To both of these gentlemen the writer is deeply grateful.

Material and methods. A number of fruit bodies of C. velutipes were found growing on the trunk of a willow tree in Ann Arbor, Michigan, in November 1931. Spores from one of these fruit bodes were collected on a sterile glass slide, and from this spore deposit was obtained a series of monosporous cultures used in the present study. In isolating single basidiospores, which are hyaline and relatively small in this fungus $(7-9 \times 3-4 \mu)$, the technique followed was that developed by Professor C. H. Kauffman and used with much success by his students (Sass, 1929).

cleate hypha showing nucleus undergoing division at junction of branch with main hypha.-Fig. 22. Short uninucleate hypha with one nucleus at its apex. Fig. 23. Pair of sister nuclei separating. One member of pair migrating into branch. - Fig. 24. Portion of chain of oidia showing that oidia may form on either side of transverse septum $w$ or with no wall between them and only gap s. - Fig. 25. Dicaryon mycelium showing pair of nuclei separating at fork in hypha. It is not known whether these were sister nuclei or nuclei of opposite sex.-Fig. 26. Three nuclei produced on dicaryon mycelium, each containing one nucleus. Nucleus $a$ has begun to divide, indicating that the long segment is probably about to break up into two or more oidia.-Fig. 27. A possible means of formation of uninucleate branches on binucleate mycelium: binucleate hypha in which a nucleus has divided at junction of branch with main hypha. Nuclei appear to be about to migrate into separate hyphal branches. Vacuoles $v$ may be noted. - Fig. 28. Formation of a clamp-connection and conjugate division of dicaryon.-Fig. 29. Second possible means of formation of uninculeate branches on binucleate mycelium: uninucleate hypha in which a clamp-connection began to form and then developed irregularly. Instead of fusing with hypha, clamp-cell $c$ has continued to grow, putting out thin uninucleate hypha.-Fig. 30. Binucleate hypha $b$, bearing uninucleate hypha $a$ which has broken up into a chain of uninucleate oidia. - Fig. 31. Binucleate hypha showing the appearance of nucleus in migration. Deeply staining material extends from nucleus. - Fig. 32. Another nucleus in migration. - Outlines of all drawings made with the aid of a camera lucida. Magnifications: Fig. 1-11, $\times 730$; fig. 12-18 and 21, 22, $\times 1030$; fig. $19,20, \times 1400$; fig. $25-32, \times 1150$. 
The monosporous mycelia were grown on nutrient agar in Petri dishes, stock cultures being kept by transferring the mycelia to slants of nutrient agar in large test tubes and in Erlenmeyer flasks of $500 \mathrm{cc}$. capacity.

The mycelium of $C$. velutipes grows very well on a medium made by dissolving $15 \mathrm{gm}$. malt extract (Merck and Co.) and $15 \mathrm{gm}$. agar in one liter of distilled water and sterilizing the medium in the usual manner. The growth of the fungus on this substratum, however, is such as to make microscopic study difficult: a luxuriant aerial mycelium is developed and the hyphae are closely interwoven forming a dense mat. Whenever microscopic examination of the fungus was necessary, Kauffman's synthetic agar was used as a culture medium..$^{7}$ On this agar the growth is vigorous but the mycelium does not form a dense mat and the individual hyphae are readily studied under the microscope. Fruit bodies bearing basidiospores were developed on both these media, but those developed on malt agar were larger and more regular in shape than those developed on Kauffman's agar.

Hanging drop cultures in Van Tieghem cells were frequently employed when it became desirable to watch the development of the fungus under the microscope.

At $25^{\circ} \mathrm{C}$. the fungus exhibits its maximum rate of growth (on malt agar) of $4 \mathrm{~mm}$. per day. As the average temperature of the laboratory during the winter months was found to be very suitable for growth (about $22^{\circ} \mathrm{C}$.), the cultures were stored in the laboratory under bell jars and were protected from direct sunlight.

Germination of the basidiospores. Basidiospores of $C$. velutipes were sown on hanging drops of nutrient agar in Van Tieghem cells. The spores germinated readily at room temperature on malt agar, Kauffman's agar, and in distilled water. Germination began about twelve hours after the spores had been sown; usually over eighty per cent of the spores germinated. During the process the spores swell slightly. A germ tube may be produced from one end or both ends of the spore, and the developing germ tube may become as wide as the spore. Various stages in germination are illustrated by figures $1-6$. About a week after the germination of the basidiospore, the mycelium to which it gives rise begins to produce oidia in a manner which will be described in detail in a later section of this paper.

Throughout the winter months of 1931 , fruit bodies were collected in the field and brought into the laboratory upon every opportunity with a view to determining whether or not the spores remain germinable after they have been exposed to low tempera-

7 This is a very satisfactory medium for the culture of many fungi and is made according to the following formula originated by the late Professor C. $\mathrm{H}$. Kauffman: maltose, $5.0 \mathrm{gm}$.; peptone, $0.1 \mathrm{gm}$.; $\mathrm{MgSO}_{4}, 0.5$ gm.; $\mathrm{KH}_{2} \mathrm{PO}_{4}, 0.25$ gm.; $\mathrm{Ca}\left(\mathrm{NO}_{3}\right)_{2}, 0.1$ gm.; agar, 15 gm.; distilled water, 1 liter. The medium has a $\mathrm{pH}$ value of about 5 , after sterilization. tures. Sometimes the fruit bodies were covered with snow and ice and had been subjected to temperatures as low as $-10^{\circ} \mathrm{C}$. Upon being brought into the laboratory, the pilei frequently revived to such an extent that within a half hour spores were shed from the gills. When the spores were sown on nutrient agar, they frequently germinated in twenty-four hours. The ability of the fruit bodies of $C$. velutipes to continue to shed spores at low temperatures has been reported by Buller (1924).

Heterothallism of Collybia velutipes. It has been shown by Vandendries (1923) and by Zattler (1924) that $C$. velutipes is heterothallic and tetrapolar. The mycelium developed from a single basidiospore is haploid; it is provided with simple cross-walls and has one nucleus in each cell. Monosporous mycelia fall into four groups according to their interfertility and intersterility reactions, the four groups being represented by the formulae $(A B),(a b),(A b)$ and $(a B)$. When compatible pairs of mycelia-e.g., $(A B)$ and $(a b)$ or $(A b)$ and $(a B)$-are allowed to intermingle on agar plates, dicaryon mycelium is developed which is provided with clamp-connections and has two nuclei in each cell.

Eleven monosporous mycelia of $C$. velutipes, Nos. s 1-s 11, inclusive, 8 were paired on agar plates in all possible combinations in the usual manner. No clamp-connections appeared on any of the mycelia until five days after the mycelia of each pair had met. The reason for the late appearance of clampconnections is not clear. In Coprinus lagopus clampconnections are developed within two days after the mingling of compatible mycelia, according to Professor Buller (1931) and judging from the writer's own experience with $C$. lagopus. While studying the diploidization process in Hypholoma melantinum, ${ }^{9}$ the writer attempted to make a cytological examination of the movement of nuclei but was foiled owing to the fact that the appearance of clamp-connections was delayed for several days after the union of the two haploid mycelia, the clamps appearing suddenly in such large numbers as to make tracing of the movement of nuclei impossible.

At the end of the second week each pairing was examined, and, on the basis of the clamp-connections, the mycelia were sorted into four groups. The results of the pairings are incorporated in table 1 , in which a plus sign indicates the presence of clamp-connections and a minus sign their absence. ${ }^{10}$

8 The letter $s$ in this notation was used to indicate that the mycelium was derived from a basidiospore in contrast to mycelia derived from oidia designated later by numbers preceded by the letter o, e.g. m-ol.

9 Owing to failure to obtain satisfactory results, this material was not published. An account of the culture of the fungus is given by Vandendries and Brodie (1933).

10 Ordinarily in making a determination of the pairing reactions in a hymenomycete it is well to employ at least twenty single spore cultures. The writer is here concerned not with examining the sexual condition of Collybia velutipes but merely with isolating mycelia belonging to the four groups for the experiments with oidia about to be described. 
The eleven monosporous mycelia have been employed in the numerous experiments recorded in the following pages. They have been kept in culture for two years, have been repeatedly transferred, and have all remained in the haploid condition.

The foregoing results confirm the statements of Vandendries, Zattler and others regarding the tetrapolarity of $C$. velutipes.

TABLE 1. All possible pairings of eleven monosporous mycelia isolated from a single fruit body of Collybia velutipes.

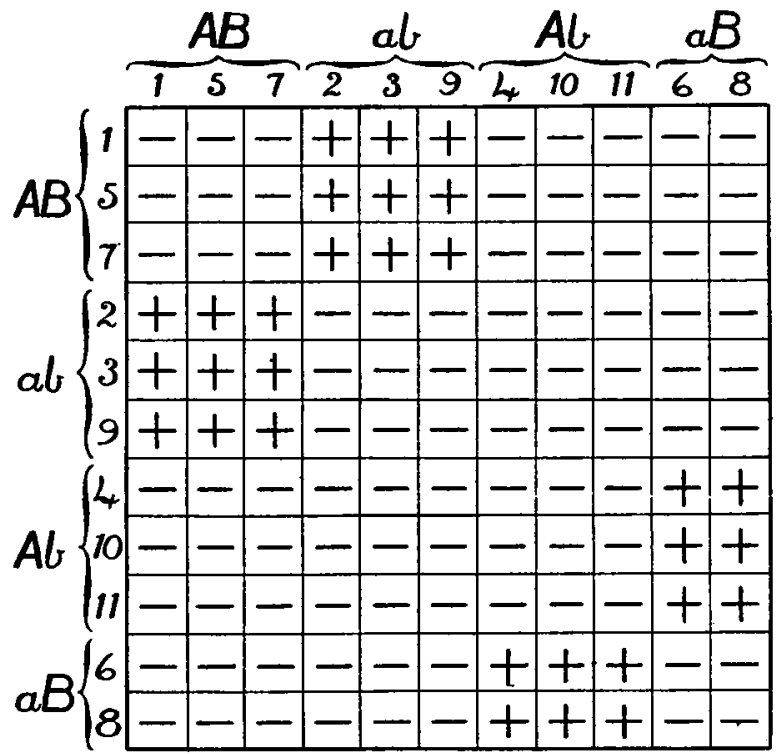

The monocaryon mycelium and the structure and development of its oidia. The mycelium which grows from a single basidiospore of $C$. velutipes is composed of relatively thin, branched hyphae which are provided with simple cross-walls (fig. 33). The appearance of such a monosporous mycelium varies according to the medium on which it is grown. On malt agar, much aerial mycelium is developed (fig. $37, B$ ) consisting of hyphae usually about $5 \mu$ in diameter. On Kauffman's agar, the fungus has a less fluffy appearance (fig. 37, A) owing to the development of fewer aerial hyphae, and the hyphae which grow within the agar and on its surface may vary greatly in diameter. Some of the older hyphae may be as much as $7 \mu$ wide while their lateral branches may be only $3-4 \mu$ wide.

The angle at which the lateral branches diverge from the main hyphae is greater in the monocaryon mycelium than in the dicaryon mycelium, but the difference between the two kinds in this respect is not marked, as will be seen by comparing figure 33 with figure 34 . In the monocaryon mycelium, usually only one branch is produced at any one point on the main hypha; but in the dicaryon mycelium, branches are usually produced in groups.

For about a week after the germination of a basidiospore of $C$. velutipes the young mycelium spreads radially over the nutrient medium but produces no oidia during this time. A portion of the actively growing region of such a young mycelium is shown in ngure 33 .

When the mycelium is about a week old, the formation of oidia begins. Certain hyphae, usually aerial branches of the main hyphae, break up into chains of short hyaline bodies, the oidia (fig. 35). Oidia are developed to a limited extent both under and on the surface of the medium but chiefly on the aerial mycelium. The oidia of $C$. velutipes are $2 \mu$ in width and vary from 4 to $8 \mu$ in length. They have dense protoplasmic contents and under the high power of the microscope bright refractive bodies can frequently be seen in the protoplasm.

The process of the formation of oidia has been watched under the microscope and it appears to be comparable to the process already described in the author's paper on the oidia of Coprinus lagopus (Brodie, 1931). However, it should be noted that the oidia are minute structures and that even with high magnification it is difficult to follow the process of their formation in living material.

A hypha which is destined to break up into oidia ceases to elongate before segmentation begins. The segmentation usually takes place in a centripetal manner, beginning near the apex of the oidial hypha; but there is considerable variation in the process, as will be shown later. The first indication that a hypha is about to form an oidium at its apex is the appearance of a thin refractive line in the protoplasm (fig. $14, a)$. About five minutes later, a vacuole appears where the line was. This vacuole enlarges until there occurs a break in the protoplasm, and the newly formed surfaces of the protoplasm become rounded off as shown in figure 14, $s$. The segment separated from the proximal portion of the protoplasm becomes an oidium. This process continues until the entire hypha has been converted into a chain of oidia. In the formation of oidia of $C$. velutipes, no liquid drops are exuded like those which have been described by the writer for Coprinus lagopus.

The formation of oidia has been frequently described, and it occurs in a great variety of fungi. Brefeld (1889) has given a description of the phenomenon as it occurs in Phlebia merismoides and other fungi. The writer has recorded observations on the formation of oidia in Coprinus lagopus. But there is still lack of complete information as to how segmentation actually takes place and how the walls of the oidia are laid down. The following observations, although not exhaustive, add to the general knowledge.

The oidia formed on aerial mycelium remain attached to one another forming chains (fig. 19). If one of these chains be immersed in water, the oidia usually (but not always) separate from one another, possibly because of the dissolution of those parts of the walls of the oidial hyphae between the oidia. The parts of the oidial hyphae between the oidia appear devoid of protoplasm. When the oidia are first formed, the wall of the hypha is easily seen. 

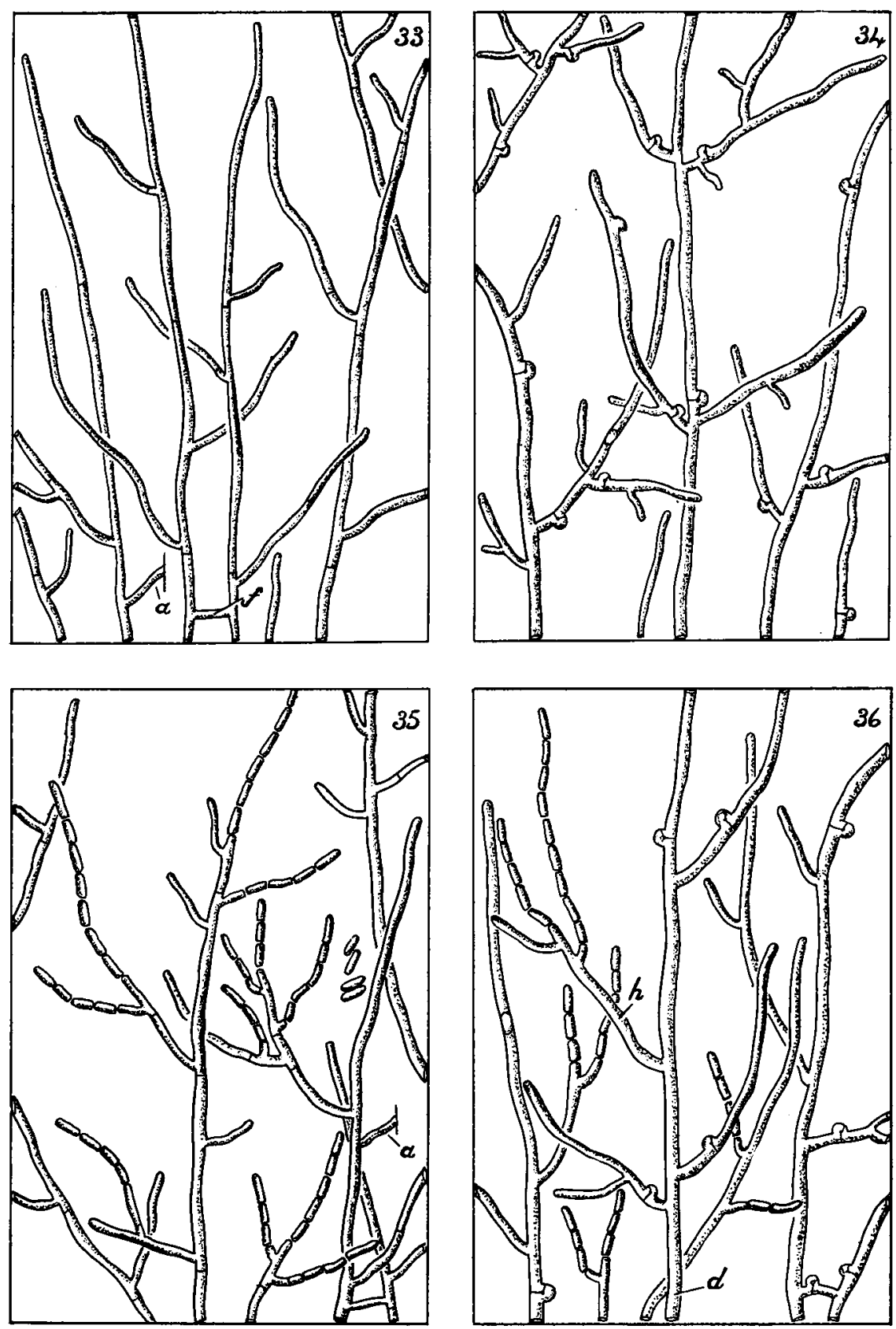

Fig. 33-36. Collybia velutipes.-Fig. 33. Portion of actively growing region of ten-days-old monocaryon mycelium: $a$, hypha which dips under medium; $f$, hyphal fusion.-Fig. 34. Portion of actively growing region of ten-days-old dicaryon mycelium showing occurrence of branches in clusters.-Fig. 35. Monocaryon mycelium about one centimeter back from tips of leading hyphae. Oidia formation is abundant. Hypha a dips under medium. All oidiabearing branches are aerial although no attempt is made to represent this in the drawing.-Fig. 36. Dicaryon mycelium just back of tips of most actively growing hyphae. Binucleate hypha $d$ has produced aerial uninucleate branch $h$ which has broken up into uninucleate oidia. There are no clamp-connections on any of the hyphal branches bearing oidia. 
As the chains of oidia grow older, however, the wall of the oidial hypha becomes less and less distinct until finally it is invisible. When the entire mycelium is stained, the oidia are deeply colored owing to the fact that they have dense contents, but between the oidia the hyphae stain only very faintly, the walls being barely discernible.

It was found that the formation of oidia takes place to a greater or lesser extent under all conditions favorable to growth. The influence of medium and temperature seem to be related to the extent of growth of the mycelium. Nor does light have any appreciable effect upon the production of oidia; for it was found that they are develoned as abundantly upon mycelia grown in the dark as upon those grown in the light.

It is well known that many kinds of mycelia break up into chains of oidia when the food supply of the medium has been exhausted. In Collybia velutipes and Coprinus lagopus, both of which have been studied by the writer, the formation of oidia is a normal specific function of the actively growing mycelium. In all the cultures of $C$. velutipes used in the present study, regardless of their age or the nature of the nutrient medium, some oidia were always produced.

Nuclear behavior during the formation of oidia on the monocaryon mycelium. Bensaude (1918) showed that in the formation of oidia on a monosporous culture of Coprinus lagopus, one nucleus passes into each oidium. The experiments of the writer using the same fungus showed that the oidia produced on monocaryon mycelium have the same sexual constitution as the parent mycelium. Kniep (1917) studied the same question in Collybia conigena and was able to demonstrate that each oidium developed on uninucleate mycelium contains but a single nucleus. It seemed desirable to try to find out in what manner a single nucleus becomes isolated in each oidium of Collybia velutipes.

Glass slides were sterilized and covered on one side with a thin film of Kaufiman's agar. Each film was inoculated with a small piece of monocaryon mycelium, and the slides were inverted over glass rods in sterile Petri dishes containing a few drops of distilled water. The mycelia were allowed to grow out over the agar for four days, after which the slides were exposed to dry air for about five minutes, allowing the film of agar to dry sufficiently so that it would not wash off later during the process of staining, but not long enough to damage the mycelium in any way. The mycelium was fixed for twelve hours in formalin acetic alcohol, stained with iron alum haematoxylin, destained with picric acid, and counterstained with light green.

Considerable difficulty was experienced in obtaining entirely satisfactory staining. The oidia with their dense protoplasmic contents stain deeply, and it was found that if destaining were carried far enough so that the nuclei in the oidia could be distinguished, then the older parts of the mycelium were completely destained and no eytological detail was discernible. Conversely, if destaining were curried only far enough to show the nuclei in the older parts of the mycelium, the oidia presented the appearance of solid black masses in which no nuclei could be seen. It was therefore necessary to destain some slides so as to show the nuclei in the oidia and others to show nuclei in the mycelium. The best differentiation of the nuclei was obtained when picric acid (saturated aqueous solution) was employed as the destaining agent.

The nuclei of the vegetative mycelium of C. velutipes, as of many other of the Hymenomycetes, are extremely small. Even with a magnification of 1220 diameters (using a 12.5 hyperplane ocular and a $2 \mathrm{~mm}$. Zeiss apochromatic oil-immersion objective) no details of the nuclei could be seen. The nuclei, when not undergoing division or migration, appear to have an inconspicuous membrane within which is a clear area and a large deeply stained nucleolus (fig. 19). It has been assumed that the nuclei which appear as heavily stained bodies of irregular shape, usually much elongated and without the clear space characteristic of the resting nucleus, are migrating (fig. $31,32)$. Migration of the nuclei frequently follows conjugate division - e.g., during the process of the formation of clamp-connections.

Although it has not been possible to demonstrate every stage in the development of the oidia and the associated nuclear phenomena, a large number of examples of significant stages have been found. In hyphal branches which show no sign of segmentation, it is common to find one nucleus, usually a short distance from the apex of the hypha (fig. 22), or two nuclei lying not far from one another, presumably sister nuclei (fig. 13). In a hypha in which the formation of oidia has begun, one nucleus appears in each oidium, and in the cell of the hypha directly posterior to the oidium farthest from the apex there is found one nucleus in a resting condition (fig. 30), one undergoing division, or a pair of nuclei lying close to one another, apparently the result of a recent division (fig. 14, $n$ ).

From these observations it seems justifiable to assume that the following events take place: $\mathrm{A}$ branch is first formed from the main hypha, a nucleus moving out into the branch (fig. 14,b). The oidial branch continues to elongate for a time and then ceases to do so. The nucleus in the oidial hypha then divides, and the apical one of the newly formed sister nuclei becomes isolated in the apically formed oidium. The nucleus remaining in the hypha again undergoes division, and again the sister nucleus nearest the apex becomes cut off in an oidium. In this way the process continues until there results a chain of oidia, each cell containing a single nucleus.

Variations in this process may occur. Frequently there is cut off, instead of the usual oidium, a segment of hypha which may be three or four times as long as an average oidium but which contains only a single nucleus. The segment may itself break up into oidia either at the same time as the formation of 

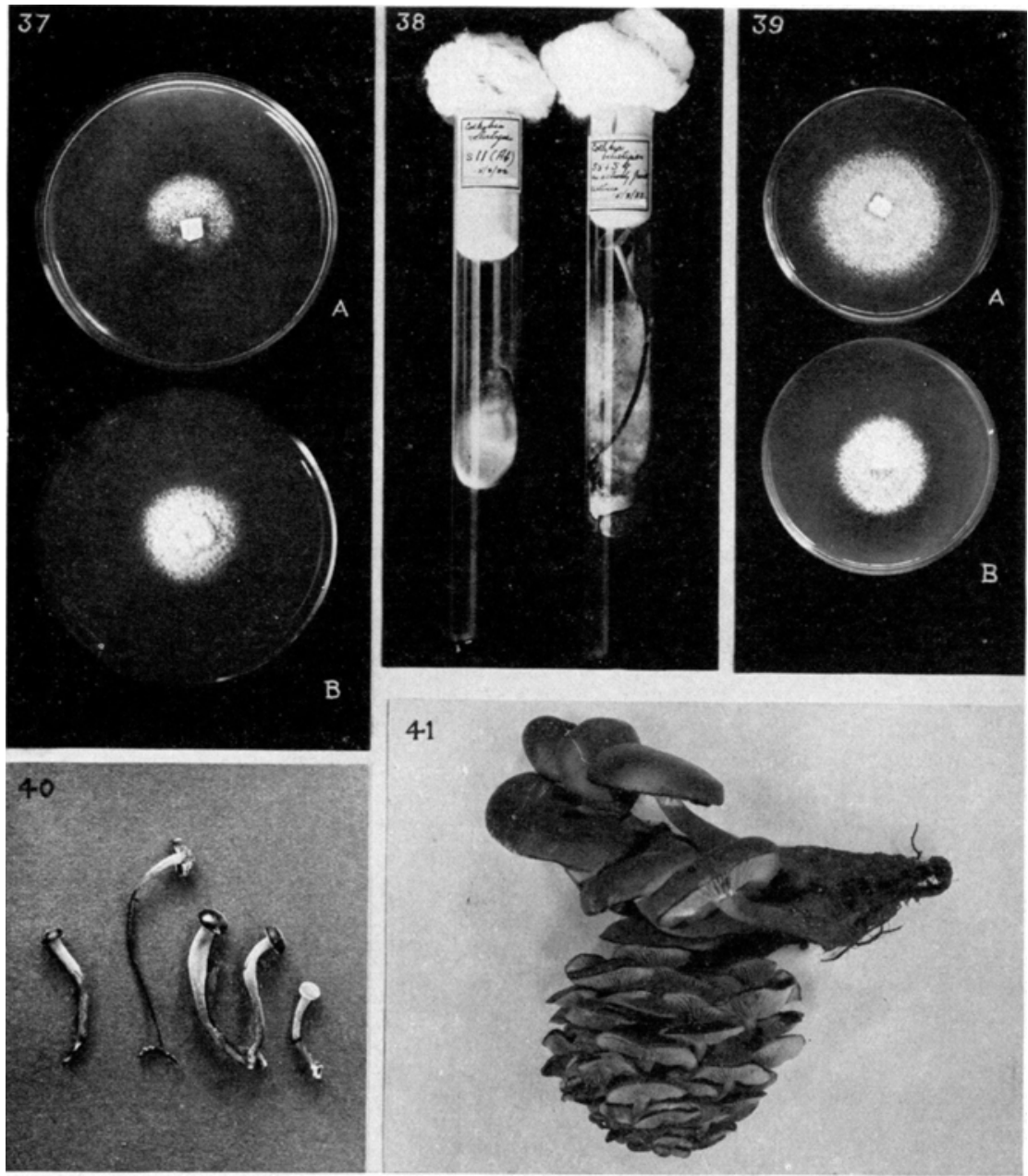

Fig. 37-41. Collybia velutipes.-Fig. 37. Comparison of types of growth of monocaryon mycelium on different media: $A$, rather sparse growth on Kauffman's agar; $B$, fluffy aerial growth on malt agar. Oidia were developed on both media.-Fig. 38. Comparison between monocaryon and dicaryon mycelia with regard to length of time required for fruit body formation. Tube on left contains monocaryon mycelium S11 ( $A b$ ), tube on right dicaryon mycelium S5-S8 $(A b-a b)$. The two tubes were both inoculated on March 15 . On April 18 the photograph was taken: dicaryon mycelium had fruited, the monocaryon mycelium had not although it did fruit later.-Fig. 39. Comparison of rates of growth of monocaryon and dicaryon mycelium on same medium. In one week, dicaryon mycelium $A$ is seen to have grown more than monocaryon mycelium $B$.-Fig. 40. Haploid fruit bodies produced in eight weeks on monocaryon mycelium S5 $(A B)$ grown on malt agar. Only tallest fruit body of the five shown produced basidiospores.-Fig. 41. Two groups of dicaryophytic fruit bodies found on a willow tree in Ann Arbor, Michigan.-Magnifications: Fig. 37, 39, 40, 41, $\times 1 / 3$; fig. 38, $\times 1 / 4$.

oidia is proceeding in the rest of the hypha, or later. Two such long segments in which the nuclei are undergoing division are shown in figures 15, a, and 26, $a$.

Again, the oidial hypha may be divided by several cross walls before the formation of oidia begins. Figure 18 shows a hypha consisting of three cells: each cell originally contained one nucleus and, in the stage in which it is drawn, the nucleus in the end cell has undergone division. Each cell would doubtless become segmented into oidia in the usual manner.

Dispersal of the oidia. That the oidia of C. velutipes may be scattered by the wind was demonstrated in the following way. A Petri dish in which a uninucleate mycelium was growing was placed on a table with its cover removed, and beside it was placed another open Petri dish containing sterile agar. A blast of air was sent over the plates in such a way that if oidia were to become detached from the mycelium, they would be blown on to the plate containing sterile agar. It was found that when a freshly opened culture plate was used, a small number of oidia were blown on to the surface of the sterile agar where they germinated and gave rise to a new haploid mycelium. However, when the culture plate 
bearing the mycelium was allowed to stand exposed to dry air for a half hour so that any excess moisture on the agar or on the mycelium would be evaporated, oidia could be blown on to the sterile plate in considerable quantities, probably owing to the aerial chains of oidia becoming more fragile when dry. We may conclude that if oidia can be blown about in the laboratory in the manner described, in nature they máy be carried off by the wind.

There is no exudate accompanying the production of oidia in $C$. velutipes such as is found in Coprinus lagopus. Therefore there does not appear to be anything about the mycelium of the Collybia especially attractive to flies and other insects which might carry oidia on their legs and bodies. Nevertheless, because the oidia adhere readily to any object brought into contact with them, it is possible that under natural conditions flies and other insects such as wood-boring and bark beetles may be agents in transferring the oidia of Collybia velutipes from tree to tree.

Germination of the oidia developed on monocaryon mycelium. The germination of the oidia of $C$. velutipes was first observed by Van Tieghem (1876). The writer has found that the oidia germinate very readily in hanging drops of nutrient agar and on agar plates. They have not been observed to germinate on the same agar substratum on which they are formed, but only after having been transferred to fresh sterile medium.

Oidia were germinated in hanging drops in a series of constant temperatures varying from $0^{\circ}$ to $45^{\circ} \mathrm{C}$. It was found: (1) that the optimum temperature for germination lies between 20 and 30 degrees Centigrade; and (2) that at temperatures below 20 degrees and above 30 , germination is greatly retarded and only a small percentage of the oidia are able to germinate at all under these unfavorable conditions.

In studying the effect of nutrient media upon the germination, it was noticed that in hanging drops of dung agar the young mycelium which developed from the germinated oidia showed a marked tendency to break up into new oidia whereas, in the malt agar drops, the mycelium showed a lesser tendency to break up into oidia anew. This is evidence in support of the idea that the nature of the substratum has some effect upon the extent of oidia production.

Stages in the germination of the oidia are illustrated in figures 7-11.

Mycelium developed from a single oidium produced on the haploid basidıosporous mycelium. Oidia were taken from a two-weeks-old culture of the monocaryon mycelium S5 $(A B)$, and from them a series of twelve single oidium cultures were made by means of the sprayed plate method. Morphologically, a tendays-old oidial mycelium is indistinguishable from a ten-days-old mycelium of basidiosporous origin. Also, the oidial mycelium grows on Kanfman's agar and malt agar at the same rate as basidiospore mycelium and in the same manner. It is interesting to note in this connection that whereas the oidial mycelium of Coprinus lagopus differs morphologically and physio- logically from haploid basidiosporous mycelium of the same species, a comparable difference is not found in Collybia velutipes.

For Coprinus lagopus the writer showed that the oidial mycelium is of the same reaction type as the parent basidiospore mycelium. Since oidia are produced by segmentation of the mycelium of Collybia velutipes, we might expect that each oidium would contain a single nucleus the genetic constitution of which would be the same as that of the nuclei of the haplophyte on which the oidia were developed.

To test the correctness of this assumption, each of the twelve single oidium mycelia was paired with each of the following four "tester" mycelia: S5 $(A B)$, S9 $(a b), \mathrm{S6}(a B)$ and S11 $(A b)$. Each of the twelve single oidium mycelia produced clamp-connection bearing mycelium only when paired with mycelium S9 $(a b)$ and they therefore all possessed the sexual constitution of the parent mycelium, namely $(A B)$.

From these results we may conclude that the oidia produced on haploid mycelium are themselves haploid and have the same reactive potentiality as the mycelium on which they are developed. This conclusion is supported by the cytological evidence given above (p. 317).

Role of the oidia and the oidial mycelia in the diploidization process in Collybia velutipes. In the heterothallic hymenomycete Coprinus lagopus, when oidia are taken from a uninucleate mycelium of one sex and are transferred by hand or by insects to a uninucleate mycelium derived from a basidiospore of opposite sex, the oidia may germinate and the germ tubes or mycelia which develop from them may bring about the diploidization of the mycelium to which the oidia have been transferred. A large number of experiments have been carried out using cultures of Collybia velutipes which show that the oidia function in a similar way in this species.

The experimental methods employed were the same as those described in the writer's previous papers (Brodie, 1931, 1932) except that no experiments were carried out to demonstrate the possible transportation of oidia by insects. It seems unnecessary, therefore, to give a detailed account of the experiments with $C$. velutipes. The results may be summarized in the following statements. It was found that: (1) two oidial mycelia of opposite sex are capable of diploidizing ${ }^{11}$ one another; (2) an oidial mycelium of one sex can be diploidized by a basidiosporous mycelium of the opposite sex; and (3) a basidiosporous mycelium of one sex can be diploidized by an oidial mycelium of the opposite sex.

Haploid fruit bodies of Collybia velutipes. That the uninucleate mycelium of $C$. velutipes is capable of producing fruit bodies bearing uninucleate basidiospores has been reported by Zattler (1924). Certain of his single spore cultures possessed the ability to produce haploid fruit bodies readily, while others did not fruit at all.

11 The diploidization appeared to be of the type described by Professor Buller (1931) for Coprinus lagopus. 
The present writer has found that, as Zattler states, only certain mycelia produce haploid fruit bodies in laboratory culture. For example, the single spore mycelia Nos. $\mathbf{S 5}$ and $\mathbf{S 9}$ have fruited from time to time whereas others, S1 and $\mathrm{S} 4$ have never fruited. Other monocaryon mycelia (Nos. S3 and S8) have produced fruit body rudiments about $2 \mathrm{~mm}$. long but these rudiments invariably soon ceased to grow and failed to develop into perfect fruit bodies.

Most of the haploid fruit bodies obtained were very much smaller than normal dicaryophytic fruit bodies. The stipe was seldom more than $2 \mathrm{~cm}$. long nor the pileus more than $8 \mathrm{~mm}$. wide. Usually the stipe was not terete and regular like that of the dicaryophytic fruit bodies but was variously twisted and flattened and the pileus was always poorly developed and often very irregular in shape. A photograph of some of the haploid fruit bodies is reproduced in figure 40.

Upon one occasion a malformed carpophore was found on an old willow tree. The specimen had a curiously convoluted cap and a short thick stipe. It was brought into the laboratory and a spore deposit obtained from it. When a large number of these spores were sown together on nutrient agar, the mycelium which developed bore no clamp-connections and was therefore assumed to be haploid. Unfortunately this particular fruit body was discarded as soon as the spore deposit was obtained from it and no cytological examination was made to corroborate the experimental evidence.

As has been stated above, Stewart (1918), Buller (1924) and others have reported the occurrence of malformed carpophores of $C$. velutipes in nature. It seems to the writer possible that at least some of the peculiar forms described may be haploid fruit bodies. This suggestion will have to be verified by a cytological and experimental examination of malformed fruit bodies found in nature.

Dicaryon mycelium and its oidia. The dicaryon mycelium of $C$. velutipes has its nuclei disposed in pairs and it bears clamp-connections. The lateral branches of this mycelium usually arise in pairs, one on each side of the main hypha, and sometimes in groups. Some of the leading hyphae of an actively growing dicaryophyte are illustrated in figure 34 . In addition to differing morphologically from the monocaryophyte, the dicaryophyte is also different physiologically in that it grows faster and produces fruit bodies in a shorter time.

A short distance back from the tips of the leading hyphae of the dicaryophyte $(1 \mathrm{~cm}$. or less), oidia are borne in great abundance. The oidia developed on the dicaryophyte resemble those of the monocaryophyte in being produced by the breaking up of the aerial hyphae.

Upon examining a dicaryon mycelium bearing oidia, it was found that clamp-connections seldom occurred on the oidial hyphae. Generally the cross-walls of the oidial hyphae were simple, a fact which at once suggested that the entire hypha bearing oidia arising on the dicaryon mycelium was in the uninucleate condition. This would mean that the oidia developed on the dicaryophyte are haploid, containing but one nucleus each.

Oidia were taken from a ten-days-old dicaryon mycelium obtained by pairing cultures S5 $(A B)$ and S9 $(a b)$ and from the oidia a series of single oidium cultures were obtained by means of the sprayed plate method. Each of the ten mycelia derived from a single oidium was found to consist of hyphae with simple cross-walls and was assumed to be haploid.

Each mycelium of oidial origin was then paired on agar plates with each of the four "tester" mycelia S5, S9, S6 and S11. The results of these pairings are incorporated in the following table in which a plus sign indicates the presence of clamp-connections in the mycelium resulting from a pairing and a minus sign their absence.

TABLE 2. Results of pairing ten mycelia each derived from a single oidium taken from a dicaryon mycelium $(A B+a b)$ with four basidiosporous mycelia of known reactive potentiality.

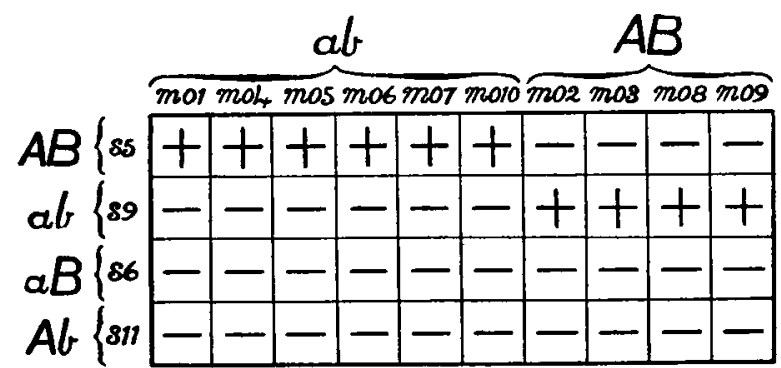

Six of the ten oidial mycelia produced clampconnections when paired with mycelium S5 $(A B)$ : these mycelia therefore had the sexual constitution represented by $(a b)$. Four of the ten produced clamp-connections when paired with mycelium S9 $(a b)$ and were therefore of $(A B)$ sex. None of the oidial mycelia produced clamp-connections when paired with either mycelium S6 or S11. This experiment was repeated several times with similar results. Of a total of twenty-nine single oidium mycelia isolated from the dicaryon mycelium $(A B+a b)$, thirteen were of the $(A B)$ kind and sixteen of the $(a b)$ kind. Similarly, when twelve single oidium cultures were isolated from a dicaryophyte obtained by pairing mycelium $\$ 6(a B)$ with mycelium $\mathrm{S} 11(A b)$, five were found to have the constitution $(A b)$ and seven the constitution $(a B)$. None were of the $(a b)$ or $(A B)$ kind.

We may conclude: (1) that the oidia produced on the dicaryophyte of $C$. velutipes are haploid; and (2) that the oidia are divided in sexual constitution so that part have the sex of one of the mycelia which was originally used to obtain the dicaryophyte, and part have the sex of the other.

In one experiment in which fourteen single oidia were isolated from a dicaryophytic mycelium, two of the mycelia resulting were found to be dicaryophytes. 
However, the writer is convinced that they arose as the result of transferring accidentally two oidia of opposite sex instead of a single oidium in each case. Out of a total of thirty-nine single oidium cultures derived from dicaryon mycelium, only the two mentioned gave rise to dicaryophytes. Also, in the stained preparations of oidia developed on dicaryon mycelium, to be described below, no instance was found of an oidium which contained more than one nucleus. Therefore the writer considers that the two dicaryon mycelia mentioned represent multioidial rather than monooidial cultures and are to be disregarded when deducting conclusions from the results.

Nuclear behavior and the formation of oidia on the dicaryon mycelium. In order to study the nuclear behavior during the formation of oidia on the dicaryon mycelium, the mycelium was grown on slides and stained in the manner already described for the haploid mycelium.

The cells of the main hyphae were found to contain two nuclei fairly regularly. Nuclei undergoing conjugate division were only occasionally found (fig. 28). In general the dicaryophyte resembled that of many other Hymenomycetes which have been studied cytologically.

It has already been observed that in the binucleate mycelium the entire branch bearing oidia may be uninucleate. This was confirmed by the examination of the stained mycelium. Clamp-connections seldom appear on an oidial hypha, or when they do occur, the clamp-connection is usually situated close to the point of attachment of the oidia-bearing branch to the main hypha. Each oidium contains only one nucleus (fig. 30). Occasionally long oidial segments were found in which there were two nuclei which appeared to have arisen from the division of one nucleus preparatory to the breaking up of the long segment into small oidia. The process by which oidia are formed appears to be identical with the process already described in connection with the haploid mycelium. This is to be expected if the oidial branches on the dicaryon mycelium really represent a return to the haploid condition.

As a result of a detailed examination of a number of slides, it seems very probable that the two nuclei of the dicaryon separate before the development of oidia in an oidial branch. The evidence which leads to this conclusion will now be adduced.

Although nuclei undergoing simultaneous or conjugate division may be demonstrated in the main binucleate hyphae, no conjugate divisions have been observed in a branch bearing oidia, suggesting that ronjugate nuclei are not present in the oidial hyphae. Wherever a pair of nuclei was observed in an oidiahearing branch, it seemed more probable (jurging from the distribution of the nuclei in the rest of the mycelium) that the nuclei were sister rather than non-sister nuclei.

In figure 23 is shown a pair of nuclei which apparently had been associated as a dicaryon. They appeared to be about to separate at the fork in the hypha. It is probable that the nuclei of the dicaryon can be separated by moving into different hyphal branches.

It may well be that the separation occurs in still another way. Let us suppose that a nucleus has moved out into the tip which would normally develop into the protuberance of the hook-cell of a clampconnection. If the nucleus were to become isolated by the formation of a wall across the hook-cell behind it, and if the hook-cell were to continue to grow as a hypha instead of fusing with the main hypha to form a clamp-connection, then a uninucleate hypha might originate. This suggestion is not based merely on supposition, for structures have been found (fig. 29) which indicate that the nuclei of a dicaryon may actually be separated from one another by the abnormal elongation of the hook-cell during the process of clamp-connection formation.

If both nuclei of a conjugate pair were to migrate into a branch and if the branch were then to begin to form oidia, oidia of both sexual strains would be borne on one branch. On the other hand, if only one nucleus were to enter an oidial branch, then all oidia borne on that branch would be of one and the same sexual strain. As has been stated, the cytological and experimental evidence strongly suggest that only one nucleus enters an oidial branch: it is nevertheless difficult to be certain of this matter. Analysis of the sexuality of each of the oidia isolated in order from a single branch would settle the question at once. Attempts to achieve such an isolation were without success. A micromanipulator of some sort. would have to be employed, and up to the present time it has not been possible to carry out this work.

It might be expected that oidia produced on a binucleate mycelium would each contain a pair of nuclei. That this does not appear to be true in $C$. velutipes is a matter of considerable theoretical importance.

Gilmore (1926) made a study of the agaric Psilocybe coprophila in culture and demonstrated that oidia are developed not only on the monocaryon mycelium but also on the dicaryon mycelium. The oidia produced by the haplophyte were found to germinate and give rise to uninucleate mycelium of the same constitution as the parent culture. But with regard to the oidia developed on a dicaryophyte (produced by pairing two haplophytes of known constitution), Gilmore concluded that: "They sometimes germinate to form diploid mycelia; at other times they germinate to form haploid mycelia, segregation of the nuclei occurring before the oidia are produced." of seventeen single oidium cultures isolated from a dicaryon mycelium, sixteen were haplophytes, only one a dinlophyte. Concerning this one Gilmore writes: "It might have originated from a small bit of diploid mycelium or two unlike oidia erroneously taken for a single germinating oirlium." It seems to the writer that if we accent the latter explanation of the variable behavior of the oidia isolated from the dicaryon mycelium, then the situation in Psilocybe 
coprophila falls into line with that in Collybia velutipes-i.e., that segregation of the nuclei does occur before the oidia are produced. ${ }^{2}$

Further evidence that segregation of nuclei in a dicaryophyte may occur with the result that uninucleate spores are produced is available. Dodge (1928), in his study of the homothallic mycelium of the ascomycete Neurospora tetrasperma, found that some of the conidia may be unisexual. He suggested that the individual nuclei of a dicaryon may become separated at some point in the development of a chain of conidia-e.g., where branching takes place, and that unisexual conidia are produced as a result.

Hanna (1929) found that when corn leaves heavily infected with the dicaryon mycelium of Ustilago zeae were floated on distilled water, branches from the mycelium grew upward through the epidermis of the corn leaves and produced aerial chains of conidia. Although the conidia were developed on binucleate mycelium, they appeared to be uninucleate. Hanna writes: "It is possible that the aerial branch growing up from a diploid hypha contains a pair of conjugate nuclei and that, when sporidia are formed, some of them receive a nucleus of one sex and others a nucleus of the opposite sex."

The separation of two conjugate nuclei of a dicaryon mycelium and the subsequent production of uninucleate spores has been shown to occur in the Ustilaginales, the Ascomycetes and the Hymenomycetes. One may ask: "Why is it that although the individual nuclei of a dicaryon in Collybia velutipes appear to have sufficient attraction for one another to cause them to remain in pairs, they may yet separate so that in portions of the growing mycelium there is a return to the monocaryophytic condition and a subsequent development of uninucleate oidia? From the evidence at hand it is not possible to answer this question and a further investigation of the matter is desirable.

Previous to 1932, no cytological study had been made of the development of oidia on the binucleate mycelium of any basidiomycetous fungus. However, while the results of the present investigations were still in manuscript, two Belgian mycologists, Vandendries and Martens $(1932,1933)$, published the results of their study of a similar problem in Pholiota aurivella Batsch. The present writer carried out his work independently and entirely without knowledge of the research of the Belgians, and it therefore becomes of interest to compare the results of two independent investigations.

Vandendries and Martens found that the dicaryon mycelium of Pholiota aurivella produces three kinds of "oidia": (1) cylindric cells developed on branched

12 Since the above was written. the author has conducted a fresh investigation of the behavior of cultures of Psilocube coprophila. He was unable to discover oidia on the dicarvon mvcelium but the latter frequently included some hyphae devoid of clamp-connections. It was not found possible to trace these haploid hyvhae to their origin. A detailed renort of this investigation will be follnd in the Canadian Journal of Research 12: 661$667,1935$. oidiophores; (2) thick walled chlamydospores; 13 and (3) fusiform oidia produced singly or in groups on short oidiophores.

A cytological and experimental study of these three spore forms was made in detail. The cylindric oidia always contain two nuclei provided by the conjugate division of a dicaryon situated in the oidiophore. Upon germination, the cylindric oidia give rise to a binucleate mycelium bearing clamp-connections. The chlamydospores contain two nuclei of opposite kind and upon germination also give rise to a dicaryophyte. The fusiform oidia consist of two cells, each cell containing one nucleus; the dicaryon is therefore separated by a septum. The two-celled oidium may germinate as a unit to give rise to binucleate mycelium, or the two cells may become entirely separated, in which case each acts as a single uninucleate oidium and gives rise to a uninucleate mycelium.

Vandendries and Martens have thus clearly demonstrated the occurrence of binucleate oidia on binucleate mycelium. This phenomenon is rare, however, as will be shown in the concluding section of this paper, and it must be admitted that oidia are most commonly associated with the uninucleate mycelium of heterothallic species.

The writer found that uninucleate oidia may be developed on the binucleate mycelium of $C$. velutipes by the separation of the two nuclei of the dicaryon before the oidia are formed. Vandendries and Martens, on the other hand, have shown that uninucleate oidia are produced on the binucleate mycelium of Pholiota aurivella by a different process: the dicaryon enters the fusiform oidium; a cross wall is formed in the oidium dividing it into two uninucleate cells, and the uninucleate cells break apart and become haploid oidia.

Comparison of Coprinus lagopus with Collybia velutipes with regard to the oidia. A comparison of the coprophilous agaric Coprinus lagopus with the wood-destroying Collybia velutipes is made in table 3.

OCCURRENCE OF OIDIA IN OTHER SPECIES OF HYMENOMYCETES - Corticium centrifugum, an Oidium producing Rot of Apples. In 1930, L. F. Butler published an account of Corticium centrifugum (Lév.) Bres. in which he reported that it is heterothallic and of the tetrapolar type. Uninucleate strains are sterile, but when compatible strains are paired, binucleate mycelium is produced bearing clamp-connections, basidia and basidiospores.

All single spore cultures were found to form oidia copiously by the segmentation of hyphae, but no oidia were found on any of the dicaryon mycelia. In this respect $C$. centrifugum resembles Coprinus lagopus, and it seemed desirable to ascertain whether or not the oidia in the apple-rot fungus are functional. The writer communicated with Dr. Butler and asked for the Corticium cultures. Unfortunately many of the

${ }^{13}$ As stated above, the term oidium as used in thi paper applies to thin walled ephemeral spores. Chlamydospores are thick walled cells whose function is to tide the fungus over unfavorable conditions and ought not to be included in the same category as oidia. 
original isolates had become contaminated and the only strains available happened to be incompatible ones.

The mycelia were found to grow well on malt agar and Kauffman's agar. The monocaryon mycelium consists of rather regular hyphae about $3-4 \mu$ in diameter. The oidia are borne chiefly on the aerial mycelium but may also occur on hyphae lying on the surface of the medium and occasionally on hyphae which are within the substratum. The oidia are produced by segmentation of the hyphae in exactly the same manner as described above for Collybia velutipes. They are illustrated in Dr. Butler's paper in figure $1, A$. seems probable that the oidia of this fungus function in the same manner as do the oidia of Collybia velutipes.

Oidia of two species of Hypholoma. ${ }^{14}$ Two species of Hypholoma have been shown to be heterothallic and to produce oidia on their monocaryon mycelia. The oidia germinate and function as in Collybia velutipes. No oidia are developed on the dicaryon mycelium of either species.

In one species, $H$. Candolleanum Fr., the oidia are peculiar in that during germination the germ tube is developed from one end of the oidium only, whereas in all other Hymenomycetes examined the germ tube

Table 3. A Comparison of Coprinus lagopus with Collybia velutipes with regard to the oidia.

1. Occurrence of the oidia

2. Exudate accompanying oidia

3. Dispersal of oidia

4. Behavior of mycelium derived from oidia of one sexual strain

5. Oidial mycelium compared with parent basidiospore mycelium

6. The dicaryon mycelium

\section{Coprinus lagopus}

In masses on ends of aerial oidiophores

Present

Mainly by insects, not by wind

Remains sterile

Dissimilar

Bears no oidia
Collybia velutipes

In aerial chains

Absent

By wind and possibly by insects

Occasionally develops fruit bodies

Similar

Bears uninucleate oidia
Some oidia were taken from the surface of a monocaryon mycelium and were transferred to hanging drops of nutrient agar. The oidin germinated readily in twenty-four hours. When oidia were sown directly on agar plates, they produced a mycelium which was in every way indistinguishable from the parent monocaryon mycelium.

An agar plate on which a monocaryon mycelium was growing was allowed to dry for a half hour by removing the lid of the plate. Upon subjecting the mycelium to a blast of air, it was found that the oidia could be readily detached from the mycelium on which they were borne, showing that wind may serve to disseminate the oidia.

Since mycelia of opposite strain were not available, no experiments other than the above were carried out. It has not been possible up to the present time to ascertain whether or not oidia of one strain, when transferred to a mycelium of opposite strain, are capable of causing the latter mycelium to become dicaryophytic, but it has been shown that the oidia are capable of germination and doubtless they may function in the way suggested.

Corticium centrifugum causes the so-called fish-eye rot of apples. According to Butler, "the indications are that infection occurs in the orchards." If a mycelium of one sexual strain were developed on the exterior of an infected apple and if oidia were developer on the mycelium, it is conceivable that either through the agency of wind or insects, the oidia might be transferred to a mycelium of opposite sexual strain and the dicaryon mycelium be produced. It may be developed from one end of the oidium or from both ends.

The oidia of $H$. melantinum are produced in compact clusters and may be surrounded by a drop of mucilaginous exudate such as has been described in connection with the oidia of Coprinus lagopus.

Oidia of three lignicolous Hymenomycetes. $-(a)$ Polystictus versicolor (L.) Fr. This fungus is heterothallic, and its oidia are produced in chains as a result of segmentation of aerial hyphae. It has been shown that the oidia germinate and function like those of Collybia velutipes. (b) Lenzites betulina (L.) Fr. This is a heterothallic fungus which produces oidia in aerial chains on the monocaryon mycelium. These oidia germinate readily, giving rise to mycelium which appears not to differ in any way from mycelium of basidiosporous origin. The fungus is peculiar in having monocaryon mycelia in which the angle of branching is small in contrast with the monocaryon mycelia of most Hymenomycetes studied in which the angle is greater than that of the dicaryon mycelia. (c) Coriolus zonatus (Fr.) Quél. In this heterothallic polypore the oidia are borne aerially on the monocaryon mycelium and form in short chains which arise from an enlarged basal portion as do the fingers of the human hand. The oidia germinate and are functional.

General discussion and conclusions. A systematic examination of the literature concerning the sexuality

${ }^{14}$ The fungi described in this section and the next were studied by the writer in collaboration with Dr. René Vandendries. The researches were recorded in La Cellule (Vandendries and Brodie, 1933). 
of the hymenomycetous fungi published from 1918 to the present time shows that of those species which have been demonstrated to be heterothallic, about twenty are reported as producing oidia (in the sense of that term as used in this paper). A list of these species follows, including bibliographic references: ${ }^{15}$

* Collybia velutipes (Curt.) Fr. (Van Tieghem, 1875a; Fidam, 1875; Brefeld, 1889; Kniep, 1917 ; Vandendries, 1923)

Coprinus curtus Kalchbr. (Brunswik, 1924)

" ephemerus Fr. (Brunswik, 1924)

“ lagopus Fr. (Bensaude, 1918; Buller, 1924, 1931 ; Brodie, 1931, 1932)

" niveus (Pers.) Fr. (Mounce, 1921)

“ radians Desm. (Vandendries, 1923)

* Coriolus zonatus (Fr.) Quél.

* Corticium centrifugum (Lév.) Bres. (Butler, 1930)

* Hypholoma Candolleanum Fr.

" hydrophilum Bull. (Kniep, 1920; Vandendries, 1930)

" fasciculare Huds. (Kniep, 1920)

* " melantinum Fr.

“ sublateritium Fr. (Kniep, 1920; Vandendries, 1934)

* Lenzites betulina (L.) Fr.

Leploporus imberbis (Bull.) Quél. (Vandendries, 1933)

Panaeolus campanulatus L. (Vandendries, 1923)

Pholiota aurivella Batsch. (Vandendries, 1932, 1933)

* Polystictus versicolor (L.) Fr. (Kniep, 1920)

Psathyra spadiceo-grisea (Schaeff.) (Kniep, 1920)

Psilocybe coprophila Bull. (Gilmore, 1926)

All these fungi save two produce oidia on the monocaryon mycelium and never on the dicaryon mycelium. Of the two which do produce oidia on dicaryon mycelium (Collybia velutipes and Pholiota aurivella) Pholiota aurivella alone has been shown to produce binucleate oidia. ${ }^{16}$

In only a small number of heterothallic species are no oidia produced in culture. Reference has been found to only four species which behave in this way. They are:

Fomes pinicola (SW.) Cooke. (Mounce, 1929)

Pleurotus columbinus Bres. (Vandendries, 1932)

" nidulans Pers. (Vandendries 1932)

Schizophyllum commune Fr. (Kniep, 1917, 1920)

It is difficult to obtain definite information regarding homothallic species of which there are but few. The writer has information concerning three of these, Coprinus sterquilinus Fr., C. stercorarius (Bull.) Fr., and $C$. narcoticus Fr. None of these fungi produce oidia (Brodie, 1931; Buller, 1931).

15 Species marked with an asterisk are those whose oidia have been described in this paper.

16 As this paper goes to press, there has just come to hand a communication by Dr. Vandendries (La polarité sexuelle et le régime conidien chez Pleurotus pinsitus; Bull. Soc. Myc. France 50:203-212, 1934) in which it is reported that the dicaryon mycelium of Plemolus pinsi'us Fr., produces conidia. The conidia contain two nuclei regularly but arise on short sterigmata-like pedicels and are not produced by segmentation as are oidia.
We may conclude: (1) that heterothallic hymenomycetes as a rule produce oidia on the monocaryon mycelium; (2) that oidia are only rarely produced on dicaryon mycelium and even then may themselves be uninucleate; and (3) that, as far as is known, homothallic Hymenomycetes do not produce oidia.

The belief of Brefeld that the oidia of the Hymenomycetes are to be regarded as vestigial structures which have lost the power of germination is not supported by the evidence presented above. In each of the eight species studied in detail, the oidia germinate readily under a variety of conditions. It is probable that all oidia produced on vigorous mycelium are capable of germination.

Experiments reported previously and in the present paper show that oidia are produced under all conditions which favor the growth of the mycelium. The production of oidia is therefore not induced by unfavorable growth conditions. The most that can be said is that environment causes a variation in the amount of oidia production.

The most important question-namely, whether or not the oidia play a definite roble in the life history and diploidization process in the Hymenomycetes in general - can be answered in the affirmative. In Coprinus lagopus (Brodie, 1931, 1932), owing to the specialization of the oidial mycelium and the failure to obtain carpophores from single oidium cultures, the conclusion was deduced that the sole function of the oidia is that concerned with diploidization. However, the study of a considerable number of fungi has shown that the specialization found in C. lagopus is not general. Oidia can and do serve to propagate the fungus vegetatively, but their most important function is that concerned with diploidization.

The interpretation to be given to the behavior of small spores such as oidia in the higher fungi appears to depend in part upon one's concept of the word "sex" as applied to the hymenomycetous fungi in which there exists no morphological distinction between the thalli which unite to form a dicaryon thallus. Kniep (1928), in his book "Die Sexualität der Niederen Pflanzen," has used the word "copulant" to designate those elements which copulate, regardless of whether the elements be nuclei, cells, or thalli. For the writer, when two copulants come together and when the two kinds of nuclei concerned fuse to form a diploid nucleus from which, after meiosis, haploid nuclei are again produced, the process of the uniting of the copulants is a sexual one.

If one is willing to extend one's concept of the word "sex" so that male and female organs are no longer criteria, then there is no great difficulty about regarding the two strains which exist in many of the Hymenomycetes as sexes. These two kinds of mycelium may be identical morphologically. We know that they differ genetically, and this difference appears to be accompanied by a physiological difference. Blakeslee's attempts to differentiate his strains of mucors by chemical tests have not given very conclusive results, and French biochemists have failed to 
demonstrate any definite difference between the sexual strains of higher fungi.

When dealing with tetrapolar sexuality, however, it becomes difficult for the conservative mind to accept the idea, frequently expressed in the literature today, that there may be four "sexes" instead of two. Lack of morphological differentiation makes it impossible to speak of "male" and "female" strains, and so it is upon a basis of compatibility and incompatibility that sexual reactions are analyzed. We have as yet no means of determining the true nature of the factors which govern the reaction of mycelia in the Hymenomycetes.

The oidia of such a fungus as Collybia velutipes ought not to be regarded as spermatia (1) because there are no corresponding female organs and (2) because they germinate and give rise to ordinary monocaryon mycelium. Oidia can and do function in ordinary vegetative reproduction; but, because they are ephemeral for the most part, it appears that their most important function is in the diploidization process. When oidia are carried from a mycelium of one strain $(A)$ to a mycelium of opposite strain $(B)$, they do not reproduce the mycelium $A$ vegetatively but serve to carry nuclei from $A$ to $B$ so that the latter becomes diploidized. In this way they are behaving sexually. However, since the oidia from mycelium $A$ are capable of reproducing it when they are sown on a substratum containing none of the mycelium $B$, they can also function vegetatively, serving for the multiplication of the gametophyte on which they are produced.

The oidia of Coprinus lagopus appear to be more highly specialized to their function as diploidizing agents than those of Collybia velutipes. In Coprinus the oidia are not transported by wind but by insects; this transportation is made more probable because the oidia are developed on oidiophores which project from the substratum into the air, and they are set free into drops of mucilaginous exudate which attract insects and cause the oidia to adhere to the legs and bodies of insects. In $C$. lagopus, further, the oidial mycelium is actually less robust than, and grows more slowly than the haploid basidiosporous mycelium.

Turning to the Uredinales, we find an analogy between the function of the pycniospores and the oidia of the agarics. The pycniospores taken from a $(+)$ rust pustule and transferred to a (-) pustule instigate the development of dicaryon mycelium in the (-) pustule and vice versa. However, the pycniospores alone do not give rise to an independent mycelium and are therefore more closely analogous to true spermatia than are oidia. Andrus (1931) claims that in the Bean Rust (Uromyces appendiculatus) there are, in addition to pycniospores, hyphae which function as trichogynes and he therefore calls the pyeniospores true spermatia or male cells.

In the Ascomycetes, the microspores in some forms such as Sclerotinia Gladioli (Drayton, 1932) apnarently function as male cells. In other forms, such as
Neurospora sitophila (Dodge, 1932), the microconidia can germinate to produce mycelium and therefore have a vegetative as well as a sexual function. It is to be expected that stages of transition between these two extremes exist and may be found.

In the group of fungi studied in the present research, we have evidence of a transition from Collybia velutipes, in which the oidia do not appear to be specially adapted to the function of diploidization, to Coprinus lagopus, where there is both morphological and, to a lesser extent, physiological adaptation to the special function of diploidization. It seems reasonable to suppose that some of the Hymenomycetes may produce oidia which are capable of serving only as diploidizing agents although the life-history of such a fungus has not as yet been described.

Among the higher plants, morphological differentiation enables us to designate certain structures as male and others as female. In a fungus where morphological differentiation has disappeared, it becomes impossible to use the terms "male" and "female."

Among the higher plants, the phenomena of selfsterility and interfertility are commonly met with. It is quite conceivable that a fungus might retain a tendency which in a higher plant we would designate as self-sterility. An example of self-sterility is found in the ascomycete Sclerotinia Gladioli, the microconidia being unable to bring about the development of apothecia on the mycelium on which they were formed but only on mycelium of reactive potentiality opposite to the first.

Among the higher plants, sexuality is not the same thing as self-sterility and interfertility; but in a hymenomycetous fungus in which all morphological differentiation between individual mycelia has disappeared, how are we to distinguish the true manifestation of sex from whatever other phenomena might attend the mating of mycelia?

Tetrapolarity may be an expression of sex plus an expression of some form of self-sterility, but if so we have no way of distinguishing between the two things at the present time. Research in progress into the cause of the mutual aversion manifest between certain monosporous mycelia of Lenzites betulina has led the writer to believe that of the two factors which govern the tetrapolar behavior of this fungus, only one is responsible for aversion (Brodie, 1936). Should it be found that the two factors are actually unlike in the manner in which they act, it might eventually be possible to distinguish between sex and other phenomena such as self-sterility and interfertility.

At present we are unable to make any such distinction, and the writer is disposed to adhere to the following ideas: (1) that bipolarity and tetrapolarity are manifestations of sex, (2) that the terms "male" and "female" ought not to be applied to mycelia or structures in the Hymenomycetes, and (3) that the oidia-while not to be considered as spermatiahave a sexual function which is of even greater importance than their purely vegetative function. 


\section{SUMMARY}

Oidia occur so commonly in the Hymenomycetes that a monocaryon mycelium which fails to produce them is a rarity.

Oidia in the group Hymenomycetes have a definite mode of formation, typified by Collybia velutipes. The process of the formation of oidia is as follows: (1) A nucleus migrates into the hyphal branch which is destined to segment. (2) The nucleus then divides. (3) A vacuole appears in the protoplasm of the hypha a short distance back from the apex and enlarges until it produces a break in the protoplasm. (4) One of the newly formed sister nuclei is thus isolated in an apically formed oidium. (5) The other nucleus again divides and the process is repeated. This process differs considerably from the ordinary process of conidia formation.

Oidia are developed on the dicaryon mycelium of $C$. velutipes as well as on the monocaryon mycelium. These oidia are uninucleate and are borne on uninucleate branches arising from the dicaryon mycelium. Such uninucleate branches are produced by the separation of the nuclei of a dicaryon either by the nuclei migrating into different branches or, rarely, by the abnormal elongation of the hook-cell during the process of formation of clamp-connections. The process of oidia formation and nuclear division is the same in these uninucleate branches as in the ordinary monocaryon mycelium. Half the oidia borne on dicaryon mycelium are of the same strain as one of the parent mycelia originally used to obtain the dicaryon mycelium, and half are of the same strain as the other parent mycelium.

The oidia of $C$. velutipes may function as diploidizing agents in the following manner: After being carried by wind or by insects from a mycelium of one sexual strain to a mycelium of opposite sexual strain, the oidia may germinate and diploidize the mycelium on or near which they have been deposited.

The function of the oidia produced on the dicaryon mycelium is the same as that of the oidia produced on the monocaryon mycelium.

Oidia are not the result of degeneration of the mycelium. On the contrary, they are developed on vigorously growing mycelia more abundantly than on mycelia growing on stale medium.

Oidia characterize the monocaryon mycelia of heterothallic Hymenomycetes and are usually uninucleate. Rarely they may be produced on dicaryon mycelium but there are only a few authenticated examples of the production of binucleate oidia by dicaryon mycelium.

Oidia may play a purely vegetative rôle like basidiospores and give rise to monocaryon mycelia which increase the chances of propagation of the species. The mycelia which arise from oidia have the same constitution as the mycelia of basidiosporous origin. Mating with one another, or with basidiospore mycelia, the oidial monocaryophytes may give rise to fertile dicaryophytes or may be affected by a dicaryon mycelium in the phenomenon of diploidization. The chances of propagation and mating are further increased owing to the fact that these monocaryophytes produce in their turn oidia which have the same characters as oidia of the first generation.

The most important function of the oidia of the Hymenomycetes is their behavior as diploidizing agents.

\section{University of Michigan, Ann Arbor, Michigan}

\section{LITERATURE CITED}

AMEs, L. M. 1932. An hermaphroditic self-sterile but cross-fertile condition in Pleurage anserina. Bull. Torrey Bot. Club 59: 341-345.

Andrus, C. F. 1931. The mechanism of sex in Uromyces appendiculatus and $U$. vignae. Jour. Agr. Res. 52: 559-589.

Bensaude, Mathitde. 1918. Recherches sur le cycle évolutif et la sexualité chez les Basidiomycètes. Thesis, Nemours. p. 1-156.

Brefeld, $O$. 1877. Botanische Untersuchungen über Schimmelpilze. Vol. III. Leipzig.

_. 1889. Untersuchungen aus dem Gesamtgebiet der Mykologie. Vol. VIII, Leipzig.

Brodie, H.J. 1931. The oidia of Coprinus lagopus and their relation with insects. Annals Bot. 45: 315-344.

1932. Oidial mycelia and the diploidization process in Coprinus lagopus. Annals Bot. 46: 727732.

1936. The barrage phenomenon in Lenzites betulina. Genetica 18: 61-73.

Brunswick, H. 1924. Untersuchungen über die Geschlechts- und Kernverhältnisse bei der Hymenomyzetengattung Coprinus. Bot. Abhnd. (Goebel) 5: 1152.
Buller, A. H. R. 1924. Researches on fungi. III. London.

—_. 1931. Researches on fungi. IV. London.

Bulliard, P. 1791. Histoire des champignons de la France. Paris.

Butrer, L. F. 1930. Corticium centrifugum, a heterothallic pathogene of apples. Jour. Agr. Res. 41: 269-294.

Constantin and Matruchot. 1894. Culture d'un champignon lignicole. Compt. Rend. 119: 752-753.

Cornu, M. 1875. Etude de la fécondation dans la classe des champignons. Compt. Rend. 80: 1461 1468.

Craigie, J. H. 1927. Discovery of the function of the pyenia of the rust fungi. Nature 120: 765-767.

Donge, B. O. 1928. Unisexual conidia from bisexual mycelia. Mycologia 20: 226-234.

- 1932. The non-sexual and the sexual functions of the microconidia of Neurospora. Bull. Torrey Bot. Club 59: 347-360.

Dowding, E. S. 1931. The sexuality of Ascoboluts stercorarius and the transportation of the oidia by mites and flies. Annals Bot. 45: 621-637. 
Drayton, F. L. 1932. The sexual function of the microconidia in certain Discomycetes. Mycologia 14: $345-348$.

EidAM, E. 1875. Zur Kenntnis der Befruchtung bei den Agaricus-arten. Bot. Zeitschr. 33: 649-653.

Falck, R. 1902. Die Cultur der Oidien und ihre Rückführung in die höhre Fruchtform bei den Basidiomyceten. Beiträge z. Biol. Pflanzen 8: 307-346.

FUNKE, G. L. 1924. Ueber die Isolierung von Basidiosporen mit dem Mikromanipulator nach Janse und Péterfi. Zeitschr. Bot. 16: 619-623.

Gilmore, K. A. 1926. Cultural studies of Psilocybe coprophila. Bot. Gaz. 81: 419-433.

Hanna, W. F. 1929. Studies in the physiology and cytology of Ustilago zeae and Sorosporium reilianum. Phytopath. 19: 415-522.

Hofmeister. 1852. Beiträge zur Kenntnis der Gefässkryptogamen. Arch. d. K. Sachs Gess. d. Wiss. Leipzig.

Karsten, H. 1860. Das Geschlechtsleben der Pflanzen und die Parthenogenesis. Berlin.

KirCh NER, O. 1875. Beobachtung des Geschlechtsorgane bei d. Gattung Coprinus. Bericht über Bot. Sect. Schles. Gess. (Cited from Bensaude, 1918.)

KNieP, H. 1917. Beiträge zur Kenntnis der Hymenomyceten. V. Zeitschr. Bot. 9: 81-118.

- 1920. Ueber morphologische und physiologische Geschlechtsdifferenzierung. Verhandl. Phys.-Med. Ges. Wurzburg. 46: 1-18.

ㄴ. 1923. Ueber erbliche Änderungen von Geschlechtsfaktoren bei Pilzen. Zeitschr. Indukt. Abstamm. Vererb. 31: 170-183.

ㄴ. 1928. Die Sexualität der niederen Pflanzen. Jena.

Micheli, P. A. 1729. Nova plantarum genera. Florence.

Mounce, Irene. 1921. Homothallism and the production of fruit bodies by monosporous mycelia in the genus Coprinus. Trans. British Mycol. Soc. 7: 198217.

- 1929. Studies in forest pathology. II. The biology of Fomes pinicola (SW.) Cooke. Dom. Canada Dept. Agr. Bull. III.

Oersted. 1865. Oversigt det. Kgl. danske. Vidensk. Selsk Forhandl. (Cited from Bensaude, 1918.)

ReEs, M. 1875. Ueber die Befruchtungsvorgang bei den Basidiomyceten. Erlangen.

SASs, J. E. 1929. The cytological basis for homothal- lism and heterothallism in the Agaricaceae. Amer. Jour. Bot. 16: 663-701.

Schmitz, F. 1880. Untersuchungen ïber die Structur des Protoplasmas und der Zellkerne des Pflanzenzellen. Sitz. Niederrh. Ges. Nat. Heilk. Bonn. 37 : 159-198. (Cited from Bensaude, 1918.)

Stwwart, F. C. 1918. The velvet-stemmed Collybia-a wild winter mushroom. New York Agr. Exp. Sta. Bull. 448.

Tulasne, L. R. 1851. Note sur l'appareil reproducteur dans les lichens et les champignons. Ann. Sci. Nat. 3e série, 15: 370-380.

VANDENDRIES, R. 1923. Recherches sur le déterminisme sexuel des Basidiomycètes. Acad. Roy. Belgique. C. Sci. Mém. 4e, Sér. 2. 5: 1-98.

1930. La tétrapolarité et les mutations sexuelles chez Hypholoma hydrophilum Bull. Bull. Soc. Roy. Belgique. 63 : 26-35.

- 1932. La tétrapolarité sexuelle de Pleurotus columbinus. La Cellule 41: 267-278.

1933. Nouvelles investigations dans le domaine sexuel des Hyménomycètes. Bull. Soc. Mycol. France 49: 130-165.

. 1934. Les affinités sexuelles de Hypholoma sublateritium Fr. Bull. Soc. Mycol. France 50: 213217.

ANd H. J. Brodie. 1933. Nouvelles investigations dans le domaine de la sexualité des Basidiomycètes et étude expérimentale des barrages sexuels. La Cellule 42: 165-209.

, and P. Martens. 1932. Oïdies haploïdes et diploïdes sur mycélium diploide chez Pholiota aurivella Batsch. Bull. Acad. Roy. Belgique. Sér. 5. 8: $468-472$.

ANd P. Martens. 1933. Le cycle conidien haploïde et diploïde chez Pholiota aurivella. La Cellule 41: 337-388.

Van Tieghem, P. 1875a. Sur la fécondation des Basidiomycètes. Compt. Rend. 80: 373-377.

- 1875b. Sur le développement du fruit des Coprins et la prétendue sexualité des Basidiomycètes. Compt. Rend. 81 : 877-880.

- 1876. Nouvelles observations sur le développement du fruit et sur la prétendue sexualité des Basidiomycètes et les Ascomycètes. Bull. Soc. Bot. France 23: 99-105.

Z A'TTLER, F. 1924. Vererbungsstudien an Hutpilzen (Basidiomyceten). Zeitschr. Bot. 16: 433-499. 